\title{
The Efficacy of Natural Honey in the Management of Second Degree Burn Complicated by Acute Dermatitis in a Diabetic Patient
}

Hashim Mohamed", Mansour Abo Salma RN, Badriya Al Lenjawi, Zaghloul Abo Gouda, Zainab Hussain, Shawkia Al Majid, Fatma Salem, AzzaMetwali and Diovanni David Mendoza

Weill Cornell Medical College, Doha, Qatar

*Corresponding author: Hashim Mohamed, Weill Cornell Medical College, Doha, P.O Box 7452, Qatar, Tel: +974 4492 8800; E-mail: fmcc2000@gmail.com Rec date: Mar 27, 2014, Acc date: May 22, 2014, Pub date: May 26, 2014

Copyright: (C) 2014 Mohamed H, et al. This is an open-access article distributed under the terms of the Creative Commons Attribution License, which permits unrestricted use, distribution, and reproduction in any medium, provided the original author and source are credited.

\begin{abstract}
Background: Foot complications are the major reason for hospital admission among diabetic patients. Natural Honey is proposed as an alternative dressing for a variety of wounds including diabetic foot ulcers, pressure ulcers, ostomy wound and central vein catheter exit wounds.

Main observations: We report a case of a 50- year- old diabetic man with an erosive -bullous eruption and hyperemia and second degree burns of both feet following the wearing of a new pair of leather sandals and the immersion of both feet in hot water whirlpool. The patient was treated with Natural Honey impregnated cotton gauzes on a daily basis and the lesions have healed after six weeks.

Conclusion: The use of Natural Honey is effective in treating allergic contact dermatitis complicated by a second degree thermal burn in a diabetic patient and offers a natural and cost effective alternative to expensive wound dressing material.
\end{abstract}

Keywords: Contact dermatitis; Diabetes; Natural honey; Primary care; Second-degree burn

\section{Introduction}

Natural Honey has been used for thousands of years to treat a variety of wounds and despite its potential to treat a variety of conditions its inclusion in the mainstream clinical practice has not been well recognized.

\section{Case Report}

A 50- year old diabetic man presented to our primary health care centre with an acute dermatitis complicated by an erosive bullous eruption and a second degree burn involving both of his feet (Figure $1)$.

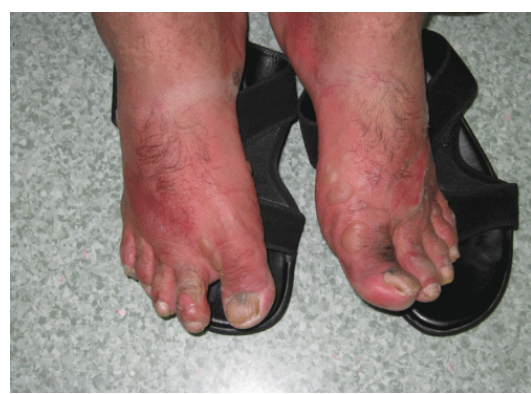

Figure 1: Bilateral feet showing several bullae, peeling of the skin and hyperaemia
History taking revealed that the patient had been wearing a new pair of leather sandals for three hours where his feet began to become hyperaemic and itchy, he consulted his wife who soaked his foot in a hot water foot bath (whirlpool), and started to rub the dorsum of his feet with a pure natural volcano stone, following which his foot began to swell with removal of the epidermis and the dermis layer (Figure 2).

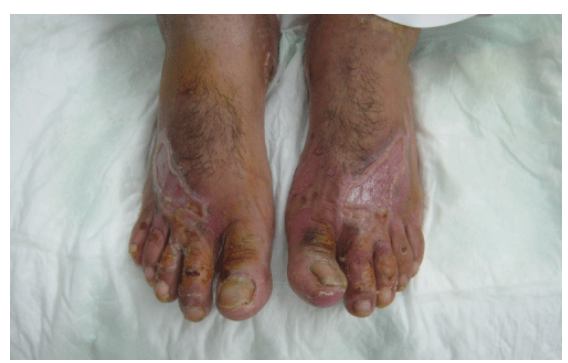

Figure 2: Post foot bath and rubbing, showing bilateral removal of the epidermis and dermis layers of the skin

The next day he presented to our health centre for consultation. Dermatological examination revealed considerable contact dermatitis, with the possibility of cellulites especially in this patient where he had diabetes for the last twenty years and the possibility of immune compromise is high. Diabetic patients may have blunted local inflammatory signs and symptoms due to leukocyte dysfunction, vascular insufficiency, and peripheral neuropathy [1]. Both feet showed several bullae and the dorsum of the feet showing peeling of the skin and the mid dorsum of the feet exhibiting injury extending into the reticular dermis measuring $2 \mathrm{~cm}$ width and $7 \mathrm{~cm}$ length and 
Page 2 of 3

hyperaemia extending from the toes to above the ankle regions (Figure 1).

Neurological examination revealed loss of protective sensations in both feet as evidenced by the use of $10 \mathrm{~g}$ monofilament where a number of cross sectional and longitudinal studies have assessed the sensitivity of the 10-g monofilament have shown it to be a useful tool to identify patients with peripheral neuropathy $[2,3]$. The lack of sensation is what caused the patient to keep his feet in the hot water bath and suffer this second degree burn. After taking a swab for culture and sensitivity, the patient was prescribed a broad spectrum antibiotic amocicillin-calvulanate to cover for staph aureus which is the most common pathogen isolated in diabetic foot wounds [4]. Afterwards the patient was counseled about different wound and burn products and opted for Natural Honey instead. The feet were washed gently with normal saline via a $10 \mathrm{cc}$ syringe and had an application of Natural honey and covered by sterile gauze. The dressing was changed on a daily basis and the burns have improved dramatically after one week where the cellulites and hyperaemia have lessened where the ulcers on the dorsum of the feet have reduced in size by fifty percent (Figure 3).

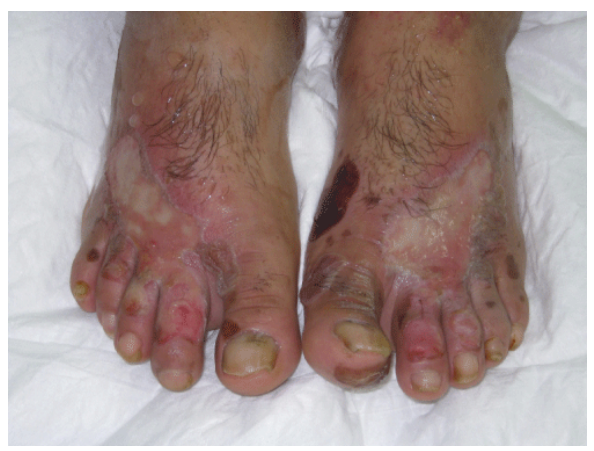

Figure 3: One week post honey dressing, showing a decrease in cellulitis and hyperaemia by fifty percent.

A week later the mid dorsum of the feet where the volcano stone was rubbed inflicting injury to the deep reticular dermis demonstrated a greenish discharge. A swab was taken by the consultant family physician with special interest in diabetes and sent to the laboratory (Figure 4).

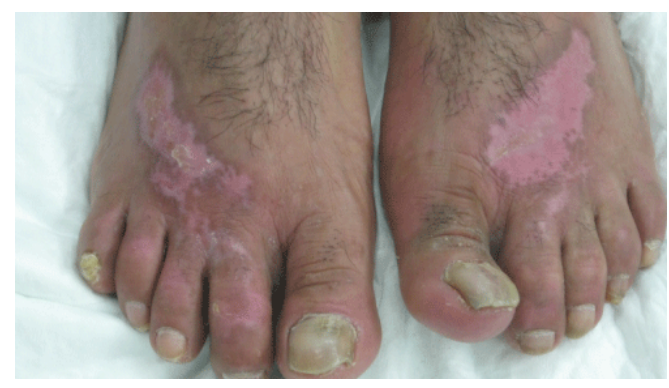

Figure 4: Four weeks later, bilateral complete healing

Culture and sensitivity showed a moderate growth of Enterobacter cloacae which was sensitive to Ceftriaxone, Gentamicin, Trimethoprim/Sulfa, and Ciprofloxacin. As a result the patient was prescribed ciprofloxacin $500 \mathrm{mg}$ twice daily and two days later the greenish discharge began to disappear and the hemorrhagic bullae on the medial aspect of the left foot has dried up and healthy granulation tissue are seen on the dorsum of both feet (Figure 3). Correction of the bioburden reduces inflammation in the wound bed while enhancing the proliferative phases of wound healing [5]. Natural Honey continued to be applied on a daily basis and four weeks later both feet have completely healed (Figure 4).

\section{Discussion}

Natural Honey has been used to treat a variety of wounds since ancient times, including diabetic foot ulcers, and post surgical wounds [6-9]. It has been suggested that the healing effect of Natural Honey is related to chemical and physical properties [10,11], including acidity, high osmolarity, volatiles organic acids, pollen, flavonoids, proppolis and hydrogen peroxide [8]. Although honey has all the above characteristics, one of the most important properties seems to be its antimicrobial action.

Antibacterial properties of Natural Honey is related to many factors including its low ph value of 3.4-6.1 [12], super-saturated content of sugars with a low water content which draws fluid out of lymphatic's and capillaries thereby enhancing wound growth through fibroblast migration and epithelization, yet at the same time depriving microorganisms of water molecules thereby compromising their metabolism [13]. Natural Honey also contains inhibin which is a thermo labile substance acting as an antibacterial factor [14], along with hydrogen peroxide, a well known antimicrobial agent, which is diluted to 1:1000 times, enough to kill most susceptible bacteria, Candida Albicans, and Methicillin resistant staph aureus.

Furthermore, Natural Honey possesses many properties which makes it the ideal dressing for a variety of wounds including its ability to absorb oedema from ulcer margins, derides wounds rapidly by the autolysis action of tissue proteases and an, create a physical barrier specially ones which contain a higher bee wax content which adds to its viscosity thereby preventing external pathogens from invading the wound. It also provide nutrients to the wound bed including laevulose and fructose, manages pain and minimize scarring has anti inflammatory properties [15] and deodorizes wounds by providing glucose to bacteria to metabolize instead of amino acids, resulting in the production of a non-malodorous metabolite, lactic acid. Furthermore, Natural Honey has an added advantage as it is easily removed from the wound bed provided you apply water or normal saline to the honey impregnated dressing prior to removal or to change the wound more often i.e. twice daily.

Our case clearly demonstrates the efficacy of Natural Honey in treating second degree burns at primary care level. The success of honey application to many wounds especially burns is partly due to the fact that Natural Honey has a significant amount of antioxidants which mops up free radicals thereby reducing inflammation and as a result prevent partial-thickness burns from turning into full-thickness burns requiring plastic surgery $[16,17]$. Other properties which makes Natural Honey an optimal dressing is its cost effectiveness especially in developing countries where diabetes has reached epidemic proportions, its ability to provide moisture to the wound bed to help cells proliferate and migrate without causing maceration to the wound edges, and the ability to be removed without causing damage to the newly formed granulation tissues. Natural Honey also contains flavonoids, propolis, beeswax, nectar, all of these properties lead to 
Citation: $\quad$ Mohamed H, Abo Salma MR, Al Lenjawi B, Abo Gouda Z, Hussain Z, et al. (2014) The Efficacy of Natural Honey in the Management of Second Degree Burn Complicated by Acute Dermatitis in a Diabetic Patient. J Diabetes Metab 5: 373. doi:10.4172/2155-6156.1000373

Page 3 of 3

minimization of scarring and stimulation of angiogenesis [18]. Furthermore, a recently published meta-analysis demonstrated that available evidence indicates markedly greater efficacy of Honey compared with alternative dressing treatment for superficial or partial thickness burns [16].

Although Natural Honey has effective antimicrobial action against many pathogens including Candida Albicans, common wound infecting bacteria such as Pseudomonas Aeruginosa, Staph Aureus, Eschericia coli and Methicillin Resistant Staph Aureus [19]. However, in our patient Natural Honey was not effective against Enterobacter Cloacae which clearly demonstrates the importance of daily assessment of the wound and any discharge or delay in the wound healing process should alert the clinician to the possibility of superimposed infections [20,21]. Post healing the patient was counseled about the importance of foot care and foot wear and the role of periodic screening in order to prevent or minimize the risk of diabetic foot complications.

\section{Conclusion}

This case report provides further evidence for the efficacy of Natural Honey in the treatment of second degree burns and contact dermatitis at primary care level.

\section{Acknowledgment}

The author would like to thank the staff at um Gwailinah health centre, Doha, Qatar for their cooperation and continuous support.

\section{References}

1. Lavery LA, Armstrong DG, Peters EJ, Lipsky BA (2007) Probe-to-bone test for diagnosing diabetic foot osteomyelitis: reliable or relic? Diabetes Care 30: 270-274.

2. Boulton AJ, Malik RA, Arezzo JC, Sosenko JM (2004) Diabetic somatic neuropathies. Diabetes Care 27: 1458-1486.

3. Mayfield JA, Sugarman JR (2000) The use of the Semmes-Weinstein monofilament and other threshold tests for preventing foot ulceration and amputation in persons with diabetes. J Fam Pract 49: S17-29.

4. Slater RA, Lazarovitch T, Boldur I, Ramot Y, Buchs A, et al. (2004) Swab cultures accurately identify bacterial pathogens in diabetic foot wounds not involving bone. Diabet Med 21: 705-709.

5. Falanga V (2000) Classifications for wound bed preparation and stimulation of chronic wounds. Wound Repair Regen 8: 347-352.
6. Mohamed H, El Lenjawi B, Abu Salma M, Abdi S (2014) Honey based therapy for the management of a recalcitrant diabetic foot ulcer. J Tissue Viability 23: 29-33.

7. Hashim M, Mansour AS, Badriya EL, Iman H (2012) Use of Honey in post excisional malignant melanoma ulcer. Journal of Lymphoedema 7 : 41-46.

8. Hashim M, Mansour AS, Badriya A, Nour B, Zaghloul G, et al. (2012) Natural Honey as an adjunctive alternative in the management of diabetic foot ulcers. Wound Practice \& Research 20: 212-216.

9. Mohamed H, Abu Salma M, Al lenjawi B, Mohammad A, Jouda Z, et al . (2014) Enhancing primary healing post Ray amputation in a diabetic patient: efficacy of natural honey. The Journal of Diabetic Foot Complications 6: 13-18.

10. Russell KM, Molan PC, Wilkins AL, Holland PT (1990) Identification of some antibacterial constituents of New Zealand Manuka honey. J Agric Food Chem 38: 10-13.

11. Snow M, Manley-Harris M (2004) On the nature of non-peroxide antibacterial activity in New Zealand Manuka honey. Food Chem 84: 145-147.

12. Basualdo C, Sgroy V, Finola MS, Marioli JM (2007) Comparison of the antibacterial activity of honey from different provenance against bacteria usually isolated from skin wounds. Vet Microbiol 124: 375-381.

13. Molan PC (1999) The role of honey in the management of wounds. J Wound Care 8: 415-418.

14. Haynes JS, Callaghan R (2011) Properties of honey: its mode of action and clinical outcomes. Clinical Review. Wounds UK 7: 50-57.

15. Hassanein SM, Gebreel HM, Hassan AA (2010) Honey compared with some antibiotic isolated from Burn-wound infections of patients in Ain Shams University Hospital. Journal of American Science 6: 301-320.

16. Tanaka H, Hanumadas M, Matsuda H, Shimazki S, Walter RJ, et al. (1995) Haemodynamic effect of delayed initiation of antioxidant therapy (beginning in two hours after burn) in extensive third-degree burns. J Burn Care Rehabil 16: 610-615.

17. Subrahmanyam M (1998) A prospective randomised clinical and histological study of superficial burn wound healing with honey and silver sulfadiazine. Burns 24: 157-161.

18. Frankel S Robinson GE, Berenbaum MR (1998) Antioxidant capacity and correlated characteristics of 14 uni floral honeys. J Apicultural Res 37: 27-31.

19. Molan P (2002) Not all honey are the same for wound healing. Bull. Eur Tissue Rep Soc 9: 5-6.

20. Wijesinghe M, Weatherall M, Perrin K, Beasley R (2009) Honey in the treatment of burns: a systematic review and meta-analysis of its efficacy. N Z Med J 122: 47-60.

21. Cooper R, Molan P (1999) The use of honey as an antiseptic in managing Pseudomonas infection. J Wound Care 8: 161-164. 